\title{
Impact of COVID-19 on Chemistry education through the online education system. A survey at the undergraduate level.
}

\author{
A. Saleem \\ Department of Chemistry, Jinnah government college, Karachi, Pakistan. \\ Corresponding Author's Email: alyyan87@gmail.com
}

\begin{abstract}
Throughout the world, chemistry is considered a challenging subject, and the number of students declines in every culture. This survey report discusses the impact of COVID- 19 on Chemistry teaching-learning and experimental studies at the undergraduate level. Also, it explores the pros and cons of the sudden implementation of the online education system on chemistry education at undergraduate-level students. Several students in third-world countries like Pakistan don't have a proper computer or laptop arrangements at their homes. They suffer more as compared to those who were facilitated with the remote system. It was observed that the recent pandemic in the form of severe acute respiratory syndrome coronavirus (SARS-CoV-2) collapsed the educational aspects around the world from fundamental to advanced levels, especially Chemistry. During this survey, numerous questions regarding the understanding of chemistry were asked to students about online classes and found more opposing towards this system. It was revealed that students became more tense as they could not understand chemistry through the online mechanism, especially the practical part. The current pandemic situation affected not only third-world countries but also developed countries. It was concluded that to cover the damage during the current pandemic, the state should take action regarding chemistry education by providing proper online and in-person education under SOPs to conduct theoretical/ practicals parts.
\end{abstract}

Keywords: SARS-CoV-2, online education system, undergraduate level students

\section{INTRODUCTION:}

In the mid of winter season, dated February $26^{\text {th }}, 2020$, Pakistan reported its first case of SARS-CoV-2, after which our country was set on emergency, which influenced numerous sectors, including domestic, cultural, political, educational, religious, and economic [1]. Among many downfalls, countries all over the world started closing their educational institutes, including schools, colleges, and universities, either private or government [2]. Global countries come up with the solution of complete lockdown resulted in cracks in the state of education, not only the surface but far deeper [3]. UNESCO reported the damage of 1.6 billion collective students of every educational level were affected in this plague, which caused an additional then 23.8 million students to leave their educational institutes, which is the worst condition that has ever been seen in history[4,5].

World Bank conducted a survey after the earthquake in 2005 (Pakistan) showed that the loss of education was equivalent to 1.5 to 2 school years after the closure of education for three months in the affected areas. Due to which $74 \%$ of parents are willing to lift the lockdown with complete SOPs [6]. World bank is also working to tackle the situation caused due to COVID-19 by collaboration with education ministers of different countries for financial support and online education development [7]. Pakistan is suffering from $3^{\text {rd }}$ highest rate of dropout primary school students in the south Asian region [8]. After the serge of SARS-CoV-2, the dynamics of the educational scenario changed drastically, which eventually generated the term "new normal." Basically, it is related to the rapid and extended use of the internet. The form of education raised rapidly after the pandemic is being called by various relatable names, i.e., online education, long-distance learning, e-learning, digital learning, remote and mobile learning. This is now becoming an essential source of education all around the world. In developing countries, online education is entirely different, and a new route of giving education is in progress. Third-world countries faced greater challenges during the pandemic and are still developing to sync with the "new world order." Pakistan needs to fill the gap created in the education sector. Several surveys, case studies, and researches have been conducted regarding the challenges and outcomes of online education systems [9-14]. Collectively it has been understood that technical, analytical, and experimental work can be accommodated through online education [15]. This article highlights the sudden implementation of an online teaching system on students who don't have this facility or were unaware of e-learning.

\section{EXPERIMENTAL SURVEY:}

To observe the impact of this pandemic at the undergraduate level, a questioner was prepared for students regarding their online/in-person education system to validate the format they prefer to adopt, conventional or online related to the understanding of the subject. 
1. Which kind of format will they prefer to adopt, conventional or online?

2. What benefits do you see in online education?

3. Any kind of loopholes identified?

4. Are you satisfied with online education?

5. Hurdles you faced to attend online classes?

6. What kind of difference in interaction with the teacher do you feel?

7. Does change in the environment influence your studies?

8. Do you agree to continue with online education in the future?

9. Do someone keeps an eye on you during online class?

10. Did mode of topic presentation from black/whiteboard to the e-device screen be accepted significantly?

\subsection{Summary of reply against questions asked:}

\subsubsection{Response \# 1:}

The majority of the students who belong to the middle class were not satisfied and unable to understand chemistry through newly imposed remote teaching due to lack of facilities. At the same time, some of them were satisfied as they were at home and safe from heavy traffic, wait, and other problems. Furthermore, some students feel that "it is convenient to have the virtual classes for studies." It gives us the benefits of location and time. In this scenario, we students can learn at his/her own pace. We can also communicate with the teacher and classmates regarding the topic in the text. The online education system also improved the attendance of the students daily.

On the other hand, the new generation of $21^{\text {st }}$-century students is more tech-savvy than the previous one. Students said that "gadgets and technologies they use collectively create an opportunity to indulge towards something wrong." These distractions may be due to domestic demands, pop-ups of different links on the screen during lectures, or a lack of understanding of the boundary of time between learning and fun. The excessive reach of the internet made things just one click away from getting the material, so, as a distraction, social media platforms are the major contributors.

\subsubsection{Response \# 2:}

The response of students who were more familiar with the internet services said that "we feel more comfortable with the Online Education System (OES), where we can also take benefit from other study tools." Every student has its area of comfort and understanding, so OES covers a broad spectrum of learning which meets almost all the needs of a student; some are sharp to understand through visualization, listening, and diagram presentation and especially for slow learners who can record the lecture and can study again.

In addition, it can benefits students like acoustic, visual, or kinesthetic. Some students' point of view was that the internet and online presentation of chemistry help them correctly visualize the shape and structure of molecules in the imagination, which benefits them to understand more efficiently. Furthermore, several students want in-person theoretical and practical classes as they haven't facility of internet/ laptop/ computer and also faced continuous electricity breakup due to which they were not happy and don't want to go in future with chemistry as the main subject.

\subsubsection{Response \# 3:}

It has been observed from the students' response that sometimes the organization administration became opportunistic and took benefit of this pandemic situation to increase their revenue by modifying the structure of learning from face-to-face to distance learning. "Some teachers were felt like struggling in the process of lecture deliverance during online class," few students replied. In addition to this, most of the students also complained that understanding chemical reactions is more difficult to understand online than a conventional method. Ignoring the bottom line of the current situation, some of the organizations are overlooking the quality education by not properly training their teachers accordingly and initiating the programs to evolve teachers' online skills. Teachers must tackle the odds of online technical aspects and grip learning management software (LMS) for more extended runs.

The darker aspect of the online education system eliminated the factor of absence from the educational institute for any reason, legitimate or not. Still, in contrast, it hiked the chances of proxy. Students laughed and made fun of this factor of what they did several times, i.e., putting the online lecture on recording and went somewhere else. It has been noticed after 
Saleem, 2021

the survey that the mobility of the student was a widespread activity. And the online system has that loophole through which one can easily dough it.

\subsubsection{Response \# 4:}

Few students who could have smartphones easily at their disposal relied on that "we agree that online education system is an inexpensive way of learning and cost-effective against transportation costs and course expenses."

But from the level of secondary education, practical performances are as important as theory. Some students also raised the issue regarding practical work and said, "We miss our science labs, where we used to do so much fun and learning by watching different chemical reactions, color-changing titration experiment and especially the lesson of exothermic reaction when a teacher showed a reaction of a piece of Sodium metal with water." The online education system may have griped the ever-dropping educational value by delivering knowledge-based education but can't fill the cavity of practical learning. Conducting practical is case-based circumstances. Fields of arts and commerce like law, auditing, accounting, and many others can prevail through knowledge-based studies, but disciplines of science weather medical or engineering like chemistry, physics, biology, neurology, medicine, mechanical, civil, electrical are practical based studies.

In view of other benefits like in big cities of Pakistan, especially in Karachi, having a problem of traffic jams. Consequently, most of the students are likely to accept the online education system due to their reduced traveling expenses and time to reach the institution. In addition to this, some students also wanted to learn in the comforts zone that their home provides but felt worried about lab works.

\subsubsection{Response \# 5:}

In response to this question, students were found complaining regarding electricity and internet facilities and replied, "most of the time when we start conduction our online, we encountered hurdle among one of them a) power failure, b) crashing the server of the host which control the program, c) a student may lose his connection, d) malfunction of electronic device, e) slowing down the speed on internet or $\mathrm{f}$ ) internet connection fails from the institute." As a result of a survey performed by the Pakistan Telecommunication Authority (PTA), only $36.86 \%$ of the entire Pakistan population has access to the internet (broadband) [16]. Even the most modern and sophisticated technologies can't be considered reliable to $100 \%$.

In all of the above conditions, students' link with the online class disconnects, and to reconnect, the individual has to massage the teacher who initiated the class. As an under-develop country, Pakistan is facing a lack of electrical power and a low literacy rate. The student complained that science subjects, especially chemistry, is sometimes hard to understand through an online class, so in any of the above-mentioned unfortunate circumstances, they could not convey their concerns and the question to clarify the concept.

\subsubsection{Response \# 6:}

Online education system allows a teacher to prepare their lecture in an efficient way to transfer the knowledge to students at the receiving ends. Few students replied that their teacher uses multiple software formats to prepare their lecture creatively, like videos, MS Office, Pdfs, 3D images, etc. It helps them enhance their imagination of understanding the chemistry topic where the 3D models are needed.

But, in many of the soft skills, communication skills can only be developed during face-to-face interactions. Students also added their opinion that subjects like chemistry feel more comfortable in conventional class than virtual. Regardless of the technology that is available today, face-to-face education is more effective than virtual studies. Without interactions with the teacher and the variety of students, the skills cannot be produced or enhanced. Online education is creating a hindrance in between remotely sitting students and the teacher at other receiving end.

\subsubsection{Response \# 7:}

Students give their response regarding this question is "in-home we feel quite comfortable and unrestricted from the barriers of conducting rules and regulations of institution, neat uniform, punctuality of time, time limits of in and out, fatigue less of being in proper shape throughout the academic timings, etc."

The online education system was, although flexible and suitable in the era of a pandemic, but still, it's a solo act of learning. It was noticed that students are mentally bored by staying at home for a long time. Suppose a virtual class consists of 30 
students; in that case, it will be an easy task to satisfy all the students participating. Neither can the student engage with their cybernetic classmates or the teacher.

\subsubsection{Response \# 8:}

The students having financial issues are the real beneficiary of the online education system because they can manage studies and work simultaneously except quitting the job. Most of the students supported online education in response and said that it relieved them from monetary burdens and helped reduce the education loans.

The online education system treats every individual as equal, which contrasts with traditional face-to-face learning. The harmony of this system sometimes lacks in addressing the difficulties and deliverance of satisfactory answers. The listening ability is more delegate and evolved as reading, but most of the students complained that "their questions asked were lost in the sea of other questions raised from the entire class."

\subsubsection{Response \# 9:}

The pros of accessibility and flexibility of the online education system also demand great responsibility from the student side. Many students replied that they are often distracted by social media applications when they start using the net. The online education system is appropriate for the students of tertiary level who have the abilities of self-motivation, time management, and organization. But the students of elementary and secondary levels are more dependent learners and encounter difficulties meeting the online paradigm's requirement.

In online education of primary and secondary level students, parental guidance is compulsory. $95 \%$ of the students admitted that no one had an eye over them when they conducted online classes. It has been noticed that most of the time during the class, parents blindly trust their children or elders to their younger sibling that they will take virtual class actively. Actually, the looking after is dependent upon the age of students and essential duty of parents to notice them timely during the class.

\subsubsection{Response \# 10:}

The online education system has become a new reality and will be inevitable for the present and subsequent years. Due to the health hazard effects of light coming out of electronic devices, parents are more concerned about their children spending hours in front of them. Students also complained regarding the damage to their eyes caused by an electrical device and health. Electronic devices emit blue light radiation that is potent for damaging human eyes. Using electronic devices and focusing on the screen may affect vision, soft muscular injuries, altered posture, headaches, or other physical issues.

On the brighter side, In Pakistan, a standard classroom has the strength of about 50 students at a time. So the back-benchers faced a common problem of not focusing on the entire black/whiteboard, resulting in a slow pace of synchronization of understanding with the teacher. Especially the students having a problem of short-distance sightedness (MYOPIA) encounter an issue to see black/whiteboard correctly.

In addition to this, the Online education system offers the edge over the conventional system regarding the curse of discrimination factors between culture, race, dress, gender, nationality, customs, language, age, physical appearance, disability, the boundary of countries, and religion.

The outbreak of this contagious pandemic left hundreds and thousands of teachers and scholars in the hand of the mercy of online education chaos [17]. After the education hostage crisis, the only solution is virtual education, which was not previously known and tried in Pakistan. At the same time, most of the teachers of chemistry did not think about distance teaching. To safeguard that education isn't bargained in the era of lockdown, both teachers and students are toying with social media applications and non-suitable forums like zoom, hangout, Edmodo, and google classroom instead of developing a professional programming solution [18]. But positively, we need to turn the table and transform the global crisis into an opportunity because the online education system is the only option left for us to stay in sync [19]. Meanwhile, the Higher education commission of Pakistan (HEC) is pushing administrations of universities towards online classes and making them sustainable. HEC also makes a legislative rule in the form of "HEC COVID-19 Policy Guidance Note 5: Online Readiness" $[20,21]$. 
Saleem, 2021

The catastrophe impact on education produced after the spread out of SARS-CoV-2, HEC continuously struggling with the need of integrating information and communication technology (ICT) demands [22]. Unfortunately, education has not been on the list of top priorities of the Pakistan Government lately. The dilemma of COVID-19 is so persistent that it will not tolerate any fragile decision about education. The only fair governance was seen on $14^{\text {th }}$ April 2021, when Pakistan launched the first-ever "television school" during the lockdowns to teach public school students [23].

\section{CONCLUSION:}

The survey revealed that Chemistry learning and teaching suffered desperately. Students face several difficulties in understanding this subject through the Online system, which was imposed suddenly. Online education has become an inevitable need for continuous and uninterrupted education. Lockdowns due to COVID-19 depreciated the education value, its liberalization, and globalization. The third-world countries already facing the stress of their economic growth seem paralyzed in policymaking to handle their education system. The low and middle-revenue countries faced a severe setback due to the sudden shifting momentum of the education system because of their limited resources, academic incompetence about future needs, and lack of educational development, organization, and management. Today, every country, especially Pakistan, is moving towards the digital transformation of their Higher Educational Institutes. Students who are sincere about their education understand the online education system is the convenient solution for survival. If the balance between the technology and its receiver is achieved, this education emergency can be converted into an advantage. In this survey, students were found to struggle with difficulties before and during cyber connections. But on the other hand, they were selfmotivated and ready to adopt the shift in the education system with a willingness for in-person practical education.

\section{Conflict of interest}

The author declares no conflict of interest.

\section{REFERENCES}

1. R. Fernando, Galle Medical Journal, 25, (2020).

2. G. Basilaia, \& D. Kvavadze, Pedagogical Research, 5, (2020).

3. G. Tam, \& D. El-Azar, (2020). https://www.weforum.org/agenda/2020/03/3-ways-coronavirus-is-reshapingeducation-and-what-changes-might-be-here-to-stay/

4. UNESCO, (2020) https://en.unesco.org/covid19/educationresponse

5. S. Dawadi, R. A. Giri, \& P. Simkhada, Online Submission, (2020).

6. Sattar, (2020). https://www.thenews.com.pk/print/684512-education-hostage-crisis

7. https://www.worldbank.org/en/topic/edutech/brief/how-countries-are-using-edtech-to-support-remote-learningduring-the-covid-19-pandemic

8. S. Abdus, (2020). https://pide.org.pk/blog/state-of-education-in-pakistan-2/

9. H. Akhter, \& M. Mahmood, Online Submission, 3, (2018).

10. A. Khalid, C. Akhtar, S. Naveed, \& S. Mukarram, Ilkogretim Online, 20, (2021).

11. I. Ahmad, International Journal of Evaluation and Research in Education, 3, 79-84, (2014).

12. N. Mumtaz, G. Saqulain, \& N. Mumtaz, Pakistan Journal of Medical Sciences, 37, 283, (2021).

13. G. Basilaia, \& D. Kvavadze, Pedagogical Research, 5, (2020).

14. L. Mishra, T. Gupta, \& A. Shree, International Journal of Educational Research Open, 1, 100012, (2020).

15. R. Azmat, Pak. J. Chem. 19, 24-25, (2019)

16. PTA, (2019). https://www.pta.gov.pk/en/annual-reports

17. J. Larreamendy-Joerns, \& G. Leinhardt, Review of educational research, 76, 567-605, (2006).

18. Jahangir, (2020). https://www.dawn.com/news/1539441

19. Li, \& Lalan, (2020). https://www.weforum.org/agenda/2020/04/coronavirus-education-global-covid19-onlinedigital-learning/

20. https://www.hec.gov.pk/english/HECAnnouncements/Documents/nCoVirus/Covid-19-Policy-Guidance-No.5Online\%20Readiness.pdf

21. K. Inayatullah, B. J. Khuda, T. Quratulain, A. M. Irfan, A. H. Imtiaz. International Journal of Innovation, Creativity and Change, 15, 1175-1195, (2021).

22. Z. A. Shaikh, \& S. A. Khoja, Turkish Online Journal of Educational Technology-TOJET, 10, 149-161, (2011).

23. K. Abbasi, (2020). https://www.dawn.com/news/1548995/ 